\section{Reply to: Understanding treatment options in craniopharyngioma better}

\author{
Hermann L. Müller
}

On behalf of my coauthors of our recent Primer (Müller, H. L., Merchant, T. E., Warmuth-Metz, M., Martinez-Barbera, J. P. \& Puget, S. Craniopharyngioma. Nat. Rev. Dis. Primers 5, 75 (2019)) $)^{1}$, I would like to thank Prof. Dr Qi for his Correspondence (Qi, S. Understanding treatment options in craniopharyngioma better. Nat. Rev. Dis. Primers https://doi.org/10.1038/s41572-020-0173-1 $(2020))^{2}$, which included the need to discuss some additional diagnostic and therapeutic considerations.

We agree and appreciate the valuable findings of Prof. Dr Qi on the anatomical relationship between craniopharyngioma and structures of the third ventricle, which definitely support and improve risk-adapted surgical approaches. On the basis of the results of multicentre studies using our grading system of preoperative hypothalamic involvement and surgical hypothalamic lesions ${ }^{3}$, we conclude that our classification of hypothalamic involvement and/or damage is feasible and provides valid risk prediction of hypothalamic syndrome and sequelae. Assessment of tumour location with regard to the mammillary bodies on preoperative MRI is recommended for planning of risk-adapted surgical approaches. More sophisticated classifications of hypothalamic location might better reflect the anatomical situation, but - based on our experience - they are not feasible for general use in a multicentre setting, owing to frequently insufficient technical quality of imaging procedures and the lack of standardization.

Only few reports conclude that gross total resection of craniopharyngioma is associated with significantly improved quality of life $^{4}$, whereas the majority of reports could not confirm this observation ${ }^{5}$. Accordingly, hypothalamus-sparing surgical approaches are currently favoured, resulting frequently in residual tumour and the necessity of further therapy. Based on a case report of Lu et al. ${ }^{6}$, Prof. Dr Qi concludes that conservative surgery with adjuvant radiotherapy will eventually result in tumour recurrence, and even malignant transformation, compromising long-term survival. However, several reports showed that local irradiation is effective in preventing growth of residual craniopharyngioma $^{7}$. Treatment of recurrent craniopharyngioma after irradiation is known to be challenging ${ }^{8}$. Surgical interventions for recurrence after irradiation are complicated by scarring due to preceding radiotherapy and by the rate of second malignancies increasing after radiation therapy ${ }^{8}$.

We agree with Prof. Dr Qi that long-term follow-up data after irradiation of childhoodonset craniopharyngioma are $\operatorname{rare}^{9}$ and, therefore, further studies analysing longterm effects of irradiation are warranted. The concept of repeated irradiation in craniopharyngioma, as mentioned by Prof. Dr Qi, should not be considered a valid option owing to radiooncological concerns regarding acute serious toxicity in terms of radiation necrosis caused by high cumulative doses and larger field sizes.

The pendulum of craniopharyngioma treatment strategies is currently swinging towards limited, hypothalamus-sparing approaches combined with postsurgical irradiation of residual tumour ${ }^{10}$. However, as pretreatment hypothalamic involvement has been shown to have independent negative effects on long-term outcome $e^{3}$, craniopharyngioma should be considered as a mainly 'chronic' disease, which cannot be cured by surgery and/or irradiation. We advocated that new therapeutic approaches should be considered to improve patients' prognosis. We definitely agree with Prof. Dr Qi that molecular research could provide such perspectives and should focus on identifying targeted treatment strategies and approaches to decrease the inflammatory reaction along the infundibulum and the floor of the third ventricle. Such an approach may enable curative treatment of this otherwise benign tumour.

Hermann L. Müller Department of Pediatrics and Pediatric Hematology/Oncology, University Children's Hospital, Klinikum Oldenburg AöR, Oldenburg, Germany. e-mail:mueller.hermann@klinikum-oldenburg.de https://doi.org/10.1038/s41572-020-0174-0

1. Muller, H. L., Merchant, T. E., Warmuth-Metz, M., Martinez-Barbera, J. P. \& Puget, S. Craniopharyngioma. Nat. Rev. Dis. Primers 5, 75 (2019).

2. Qi, S. Understanding treatment options in craniopharyngioma better. Nat. Rev. Dis. Primers https://doi.org/10.1038/s41572-020-0173-1 (2020).

3. Muller, H. L. et al. Post-operative hypothalamic lesions and obesity in childhood craniopharyngioma: results of the multinational prospective trial KRANIOPHARYNGEOM 2000 after 3-year follow-up. Eur. J. Endocrinol. 165, 17-24 (2011).

4. Hidalgo, E. T. et al. Quality of life, hypothalamic obesity, and sexual function in adulthood two decades after primary gross-total resection for childhood craniopharyngioma. Childs Nerv. Syst. 36, 281-289 (2020).

5. Fjalldal, S. et al. Detailed assessment of hypothalamic damage in craniopharyngioma patients with obesity. Int. J. Obes. 43, 533-544 (2019).

6. Lu, Y., Qi, S., Peng, J., Pan, J. \& Zhang, X Malignant transformation of craniopharyngioma in an infradiaphragmatic case. Chin. Med. J. (Engl.) 127, 3187-3188 (2014).

7. Eveslage, M. et al. The postoperative quality of life in children and adolescents with craniopharyngioma. Dtsch Arztebl. Int. 116, 321-328 (2019).

8. Klimo, P. Jr, Venable, G. T., Boop, F. A. \& Merchant, T. E. Recurrent craniopharyngioma after conformal radiation in children and the burden of treatment. J. Neurosurg. Pediatr. 15, 499-505 (2015).

9. Greenfield, B. J. et al. Long-term disease control and toxicity outcomes following surgery and intensity modulated radiation therapy (IMRT) in pediatric craniopharyngioma. Radiother. Oncol. 114, 224-229 (2015).

10. Sainte-Rose, C. et al. Craniopharyngioma: the pendulum of surgical management. Childs Nerv. Syst. 21 , 691-695 (2005).

Competing interests

H.L.M. has received reimbursement of participation fees for scientific meetings and continuing medical education events from the following companies: Ferring, Lilly, Pfizer, Sandoz/ Hexal, Novo Nordisk, Ipsen and Merck Serono. He has received reimbursement of travel expenses from Ipsen and lecture honoraria from Pfizer. 